\title{
G. E. MOORE ON CONCEPTS AND JUDGMENT ${ }^{*}$
}

\section{G. E. Moore sobre conceptos y juicio}

\author{
SEBASTIÁn BRiceÑo ${ }^{a}$ \\ https://orcid.org/0000-0003-3040-4869 \\ jsbricen@gmail.com \\ ${ }^{a}$ Universidad de Santiago de Chile, Santiago, Chile
}

\begin{abstract}
In "The Nature of Judgment" (1899), G. E. Moore defends the strange thesis according to which "[i]t seems necessary... to regard the world as formed of concepts". Philosophers have offered distinct understandings of this proposal, in particular of what Moorean concepts really are. In this article I discuss and reject three of them: one, according to which Moorean concepts are universals within the framework of a bundle theory of concrete particulars (Nelson, 1962; Baldwin, 1990); a second one, according to which Moorean concepts are particulars within a mereological framework of analysis (Bell, 1999); and a third one, according to which Moorean concepts are a sui generis category, resulting from his alleged rejection of the substance (particular)/attribute (universal) distinction (MacBride, 2018). I end by defending my own understanding, which highlights the openly Platonic stance of the young G. E. Moore.
\end{abstract}

Key words: Concepts; Judgment; Proposition; Abstract; Particular; Universal; Substance.

\section{Resumen}

En "The Nature of Judgment" (1899), G. E. Moore defiende la extraña tesis según la cual "[p]arece necesario... entender al mundo como formado de conceptos". Los filósofos han ofrecido distintas comprensiones de esta propuesta, en particular de lo que los conceptos mooreanos realmente son. En este artículo discuto y rechazo tres de ellas: una, según la cual los conceptos mooreanos son universales dentro del marco de una teoría del cúmulo sobre particulares concretos (Nelson, 1962; Baldwin, 1990); una segunda, según la cual los conceptos mooreanos son particulares dentro de un marco de análisis mereológico (Bell, 1999); y una tercera, según la cual los conceptos mooreanos son una categoría sui generis, resultante del supuesto rechazo de la distinción substancia (particular)/atributo (universal) (MacBride 2018). Finalizo

" I am grateful for the helpful feedback from audiences at the VI Colloquium on Analytic Metaphysics in Buenos Aires and at the XIX Jornadas Rolando Chuaqui in Concepción. This paper has been written as part of the research project Fondecyt Regular 1200002, ANID, Chile. 
defendiendo mi propia comprensión, que resalta la postura abiertamente platónica del joven G. E. Moore.

Palabras clave: Conceptos; Juicio; Proposición; Abstracto; Particular; Universal; Substancia.

\section{I}

"The Nature of Judgment" (hereafter $N J$ ), one of G. E. Moore's earlier articles, was published in 1899, when he was in his twenties. It was a chapter taken from a dissertation that secured him a "Prize" Fellowship at Cambridge, after having failed in a first attempt (Moore, 1968, pp. 20-22). Moore didn't republish the article, and what he says about it in his autobiography is not much: "though I am sure that article must have been full of confusions, I think there was probably some good in it" (1968, p. 22). Yet by the time he wrote it, he did seem quite excited and optimistic about its contents. He wrote to MacCarthy:

I have arrived at a perfectly staggering doctrine: I had never seen where my principles would lead me. An existent is nothing but a proposition: nothing is but concepts. There is my philosophy... I am pleased to believe this is the most Platonic system of modern times... (quoted in Preti, 2013, p. 187; my italics)

Russell also had a great opinion about the article, and he maintained it over the years. In My Philosophical Development, recalling his own break with idealism, he writes:

It was towards the end of 1898 that Moore and I rebelled against both Kant and Hegel. Moore led the way, but I followed closely in his footsteps. I think that the first published account of the new philosophy was Moore's article in Mind on "The Nature of Judgment". [...] I felt it, in fact, as a great liberation, as if I had escaped from a hot-house on to a wind-swept headland. I hated the stuffiness involved in supposing that space and time were only in my mind. [...] I have never again shut myself up in a subjective prison. (1959, pp. 54, 61, 62)

Years later, Ryle, although adding harsh criticisms, had words of praise for $N J$ too: "[It] could be described as the De Interpretatione of early twentieth-century Cambridge logic" (1970, p. 90). 
It is true that the article triggered a liberation from the "subjective prison" associated with the distinct variants of idealism (better said: mentalism) still dominant by those days. From an historical point of view, $N J$ does represent a turning point, the birth of a new philosophy. But it is not the case that argument and clarity won over metaphysical dogmatism and obscurity. At various points of NJ, Moore's ideas are presented as dogmatically and obscurely as his idealist predecessors may have presented their own. One thing is clear though: Moore, with or without reason on his side, was defending something of an obviously different sign. To the various forms of holism and subjectivism of his predecessors, he opposed a radical pluralism and objectivism. Moore's predecessors understood judgment as an organic whole, which included both the act of judging and the object of judgment as internally related parts or as mere abstractions from that whole. In reaction, Moore separated the act of judging and its object, removing all traces of psychologism from the latter, and understood them as distinct and externally related entities, for, as he thought, in order to judge that something is the case, something must $b e$ the case first. This, the object of an act of judgment, is the judgment itself, i.e., the proposition itself, which is ontologically independent from, and more fundamental than, any psychological fact or act of judgment.

The proposal defended in $N J$ is quite perplexing. Its main thesis is this: "It seems necessary, then, to regard the world as formed of concepts" (NJ, p. 182). To be clear, Moore is not saying that the world is formed, among other things, of concepts. Nor is he defending what could be called a form of "Priority Conceptualism", that is, a thesis according to which there might be derivative things that are not concepts, but only insofar as they are somehow grounded in fundamental things which are concepts (cf. Schaffer, 2010). Moore understands the world as formed of concepts, and nothing but concepts, and necessarily so. The only things in Moore's ontology that we could call "derivative" or "grounded" are just more concepts, namely: complex concepts, among which we find true and false judgments, i.e., true and false propositions, and other complex concepts which presumably are not judgments but are still analysable into other concepts, like the concept house, which might be said to be made up of the concepts door, window, wall, etc. Thus, everything, every object, is a concept. Complex concepts, insofar as they are ultimately "formed" of simple concepts, might be said to be "grounded in" or "constituted by" other concepts. But I want to remain neutral on what precisely is the relation that holds between simple and complex concepts. Because it is not even clear that Moore took complex concepts as distinct existents. He might well have thought that a complex concept (say, the complex 
concept F) was nothing over and above many simple concepts (say, many simple concepts F-related). What is very clear is that simple concepts are the building blocks that Moore offers us and that, according to him, things become intelligible only once analysed into the simple concepts out of which they are ultimately made of ( $N J$, p. 182).

How can we make sense of Moore's main thesis? In particular, how can we make sense of Moorean concepts, the single category of entities that exhaust his ontology? What are they, really? This interpretative problem is pressing. On one hand, Moore's main thesis seems, prima facie, just weird, a "rather strange and complex" ontology (Hochberg, 1962, p. 365), a "bizarre metaphysics" (Nelson, 1967, p. 373), which, among other oddities, seems to show a blatant confusion between sense and reference, meaning and denotation (Ryle, 1970, pp. 97-100). Baldwin qualifies it as plain "nonsense" and claims that when Moore attempted to explain it to Russell, he "only succeeded in displaying the incoherence of his thought" (Baldwin, 1990, pp. 41-42). On the other hand, even if one leaves its weirdness aside and takes the main thesis of $N J$ at face value, it is utterly difficult to make sense of it. Eklund (2017) identifies at least three interpretations of Moore's main thesis, and he remains undecided, since none of them seems consistent with everything Moore said. MacBride (2018) also recognises three interpretations, only one of which coincides with one of the three recognised by Eklund. And these theses do not seem to exhaust all the possibilities; at least there is room for overlapping and synthesis.

My aim here is to identify and discuss three interpretative theses, the ones that seem to me more salient, plausible and clearly delineated (sections II, III, and IV), against which I will defend my own (section V). My understanding might not be consistent with everything that Moore said, and might partially overlap with other interpretations, but it makes more sense of more things that Moore said than the other alternatives. Or so it seems. My interpretation attempts to make sense of what Moore actually said, not of what he should have said. This implies, mainly, to avoid as far as possible the charge of inconsistency; resist the temptation of importing our own ontological expectations into NJ; and take very seriously Moore's own stance on the metaphysics he was defending back then.

\section{II}

Here is perhaps one of the most obvious and dominant ways to understand Moorean concepts: concepts are adjectival universals, and Moore is advancing the understanding of concrete particulars embraced 
by the bundle theory of substance. This is surely the interpretation defended by Nelson:

There are no absolute particulars; only relative particulars, i.e., particular combinations of universals. All that there is, all that we perceive or know, consists ultimately of simple concepts, which are completely independent of each other and of any substantive thing, like mind or judgment.

[W]hatever Moore may be doing and however wrong it may be, it is obviously nothing resembling nominalism. If a name is to be applied to Moore's ontology of 1899, it might be termed "Absolute Reductive Realism", for whereas nominalists would say that all that there are in the last analysis are particulars, Moore is saying that all that there are in the last analysis are simple concepts, or adjectival universals. [...] Moore, if he is reducing anything to anything else, is reducing particulars to universals. (Nelson, 1962, p. 128)

There is clear support for this interpretation in the following important passage:

The material diversity of things, which is generally taken as startingpoint, is only derived; and the identity of the concept, in several different things, which appears on that assumption as the problem of philosophy, will now, if it instead be taken as the starting-point, render the derivation easy. ( $N J$, p. 182)

By all lights, "the problem of philosophy" that Moore is talking about is the problem of universals, or at least one main expression of it, namely: how can many numerically distinct concrete particulars resemble each other. If concrete particulars are understood as bundles of universals, the mystery is somehow dissolved. After all, they are only "relative particulars", they are, ultimately, just combinations of universals, which are multiply instantiable qualities. Identity of qualitative content is the point of departure; numerical diversity of so-called "concrete particulars" is reached by adding more distinct universals to the whole picture.

However, there is an obvious trouble with this interpretation, namely: that Moore seems to admit numbers, points or regions of space, and instants or intervals of time in his ontology ( $N J$, pp. 180, 186188). And these, like everything else, are meant to be concepts too. Yet 
numbers, times, and places are usually taken to be paradigmatic cases of particulars, not of universals. ${ }^{1}$ They seem to be what Nelson calls absolute particulars. True, they are not concrete particulars, if by being concrete we understand being spatiotemporally, or at least temporally, located. ${ }^{2}$ We can say they are abstract particulars then, just like some philosophers do, but particulars nonetheless. ${ }^{3}$

Baldwin, who also understands Moore as defending a bundle theory of concrete particulars, acknowledges this fact, and he makes sense of Moore's position by introducing a slight amendment:

The way to make some sense of Moore's nonsense is to interpret him as treating material objects as sums of their properties, and then treating these sums of properties as conjunctions of true propositions, which concern the existence of a property, or concept, at points of space and time. (Baldwin, 1990, p. 42)

Baldwin, like Nelson, interprets Moore as claiming that concrete particulars are bundles of universals; but he, unlike Nelson, admits that spaces and times (and we should also add numbers, which Baldwin doesn't mention in this respect but which Moore includes in his ontology) cannot be understood as universals. Treating them as universals is just an inconsistency, a main part of Moore's "nonsense". As Baldwin puts it, spaces and times (and numbers, as I say) simply are not "inherently general", as concepts qua universals are supposed to be (1990, p. 42).

Anyhow, Baldwin's amended interpretation still has its own problems.

Firstly, admitting that Moore was inconsistent or nonsensical must be a last resource. Interpretative charity imposes us the duty to make sense of what Moore said in a way that avoids nonsense as far as possible.

${ }^{1}$ Here I am distinguishing numbers like 2, which figure as constituents of propositions like $<2$ is a prime number $>$, from numerical properties like being two, which I understand as a plural property instantiated by any two distinct objects (cf. Frege, 1980, §§55-61; Yi, 1999).

${ }^{2}$ If the mark of the concrete is to be located in space or time, then spaces and times cannot count as concrete. They are precisely part of what grounds the concreteness of concrete things. To count them as (relatively) concrete would require the existence of meta-spaces or meta-times.

3 Lowe (1998, p. 155) and Simons (1994) do so. Sets also can be called "abstract particulars" under this use of the label. Of course, this use is to be contrasted with the one made by other philosophers, such as Campbell (1990) and Williams (1953), who take the label "abstract particular" as a name for tropes. I will come back to this later. 
Secondly, if one adds to their "inherent generality", the fact that universals must also be predicable, adjectival, attributive, or unsaturated, as they are usually understood by the bundle theorist, then Moorean concepts are certainly not universals. In fact, they are the opposite of that. In a key passage, Moore explicitly takes distance from this common understanding of universals:

A concept is not in any intelligible sense an "adjective", as if there were something substantive, more ultimate than it. For we must, if we are to be consistent, describe what appears to be most substantive as no more than a collection of such supposed adjectives: and thus, in the end, the concept turns out to be the only substantive or subject, and no one concept either more or less an adjective than any other. (NJ, pp. 192-193)

Thus, Moorean simple concepts are substantial, at least in the following senses: they are fundamental; they are not grounded on something else; they are not ontologically dependent on something else; there is nothing more ultimate than them; they are in no sense adjectival to something else; they are not "in a substance", or "said of" a substance; they are saturated. What might seem to be more substantive-e.g., water, Mark Twain, this tree, that desk-is, really, "no more than a collection of such supposed adjectives" ( $N J$, p. 192). (I will discuss this in more detail in the last section.)

Thirdly, Baldwin's amendment is incapable of offering a proper response to the following crucial aspect of Moore's proposal: Moorean concepts are called to do more and more fine-grained work than just being the building-blocks of concrete particulars. (i) In the first place, Moore clearly distinguishes between being and existence: "the concept can be consistently described neither as an existent, nor as part of an existent" ( $N J$, p. 181). All concepts are; only some of them also happen to exist. More accurate: what exists is a by-product or a combination of what is. Thus, "an existent is seen to be nothing but a concept or complex of concepts standing in a unique relation to the concept of existence" (NJ, p. 183). Something, say a horse, only exists when the concept horse is suitably related with the concept existence and with a time-concept like October $12^{\text {th }}, 1492$. But notice that existence and times are concepts too! According to Moore, we can only make sense of existent things through things that have being. But Moore's goal is to make sense of things that go way beyond the realm of existents. These latter, after all, form only a tiny subset of reality, since reality includes many concepts, 
simple and complex, not suitably related to the concept existence nor to time-concepts. Existence can only be understood by reference to true propositions ( $N J$, p. 180), but not all concepts are propositions (for instance, the concept horse is not) and not all true propositions involve the concept existence (for instance, <blue is darker than yellow $>$ and $<2+2=4>$ do not). (ii) In the second place, Moorean concepts are supposed to play the role not only of sparse properties but also of abundant properties. That is, Moorean concepts are not only responsible for accounting for facts like objective resemblance or causal powers, but they are also meant to be the possible content for all our meaningful thoughts or expressions. ${ }^{4}$ For Moore, a concept is a "universal meaning", a "content", "the symbolized" ( $N J$, p. 177), "something which we mean" ( $N J$, p. 180), a "logical idea" ( $N J$, p. 193). Moorean concepts are meant to be "possible objects of thought" (NJ, p. 179), the kind of things toward which our mind is immediately directed when judging, and they are as fine-grained as any content must be to perform such a role. If Moorean concepts are meant to be semantic values, then surely there are more of them than universals making-up, or even possibly making-up, concrete particulars. Coarse-grained properties, as usually conceived by bundle theorists, are incapable of performing such a fine-grained role.

Though Moorean concepts play the role of meanings, they do not point towards something other than themselves, that is, they do not stand for some more concrete entity, they are not modes of presenting something distinct from themselves. Unlike Fregean senses, they are not inherently representational, intentional, relational or the like. There is nothing "underneath" them to be represented by them: concepts are what makes up the world; they are referents too, immediate constituents of true (and false) propositions. Reality, according to Moore, is not divided into distinct parcels, say a realm of sense and a realm of reference; or a

${ }^{4}$ Sparse properties are those that, allegedly, ground the objective resemblance and the causal powers of things, whereas abundant properties are entirely miscellaneous and there is one for any possible predicate or thought. To illustrate it, compare the presumably sparse property being red with the presumably abundant property being red or blue. If being red constitutes, along with other properties, the nature of a concrete particular, say that rose, and is responsible for the objective facts of resemblance into which that rose enters, we don't need to add to the list of those properties the disjunctive property being red or blue. A disjunctive property is not a sparse property; it is not the sort of property responsible for facts of objective resemblance, metaphysical make-up, causal profile, etc. of a concrete particular. But being red or blue is a perfectly good abundant property: it is the semantic value of a perfectly meaningful predicate, it is a meaning, a content, which is distinct from being red, and distinct from being red or white. See Lewis (1986, pp. 59-69). 
realm of sensible objects, a realm of subjectivity and a realm of objective thoughts. Concepts are things-in-themselves, and both mind and world are exclusively made of them. In Moore's ontology, there are neither veils nor gaps between what is thinkable and reality as such or between reality as such and us. Reality itself $i s$ what is thinkable, and our minds and the so-called sensible world are part and parcel of it. ${ }^{5}$ Moorean concepts could be called thinkables. ${ }^{6}$

In Moore's ontology, strictly speaking, we don't find what we commonly understand as bundles of universals, that is, universals being multiply located here and there conforming distinct "blobs" or collections that we identify with ordinary objects, from which we then

${ }^{5}$ Using Fregean terms, one and the same concrete particular or sensible object, one and the same bundle, could be presented in different meaningful ways, just like the planet Venus could be presented through different meaningful ways, such as the morning star and the evening star. But we don't want to say that Venus is made-up of, or constituted by, those meaningful ways, those modes of presentations. They could not, since concrete particulars and their modes of presentation inhabit different realms. However, since Moore, in contrast with Frege, offers no distinction between the reference (or denotation) and the sense (or meaning) of an expression, we cannot say, that the morning star and the evening star are two modes of presentation of the same referent. Since we have a flat, one-level ontology, an ontology in which everything is a concept, we should better say that if the evening star and the morning star are two distinct senses, then they are two distinct objects, precisely because they are different objects of thought; and there is no third entity, inhabiting a realm of reference conceived as distinct from the realm of sense, to secure that it is the one and the same thing that is presented in those two different ways. We just have those different ways. In this sense, Moore's picture is like a Platonic or Fregean heaven without anything underneath, so it makes little sense to call it a "heaven" or a "third realm". Moorean concepts cover at once the realm of what is thinkable, the realm of subjectivity and the realm of sensible objects; they exhaust the unrestricted domain of quantification. This might sound blatantly false. But here I am not trying to defend the truth of Moore's account; I am only interested in making the best sense of it.

${ }^{6}$ I borrow the expression "thinkables" from Hornsby (1997), who also makes a solid defense of the idea that there is no gap between reality as such and what can be thought. Interestingly and somehow ironically, Moore's metaphysics could be classified as a form of absolute or objective idealism, just like the metaphysics of those late philosophers that Moore and Russell were rebelling against was classified. After all, Moore's reality is thought-like. However, in the first place, Moore was offering a pluralistic conception of reality, a form of conceptual atomism, whereas those late idealists offered holistic conceptions of reality; in the second place, Moore was trying to give an account of reality in terms that ultimately make no reference to the mental (consciousness, the psyche, the subject, experience, qualia, etc.), whereas those late idealists gave accounts of reality precisely in terms that made irreducible reference to the mental. In this last respect, Moore's peculiar form of absolute or objective idealism seems closer to Hegel's panlogism than to Bradley's panexperientialism or Royce's personalism. See Basile (1999: ch. 6). 
make abstraction of judgments involving predication. In contrast, Moore's ontology is already judgment-like, ready-made for thought. Using an analogy, Moorean concepts are more like the common nodes or vertices of many overlapping graphs. The concept red is not multiplylocated here and there, but it is a single concept that stands in multiple relations with other concepts, among which are the concepts here and there, forming thus complex concepts, among which there are true and false propositions.

\section{III}

Here is a second relevant interpretation of Moorean concepts: they are particulars. This is the interpretation that has been defended by Bell (1999). Since the young Moore, according to Bell, used the part/ whole framework as his exclusive framework of analysis, he couldn't but be a particularist. In Bell's words:

[A] problematic distinction within a whole/part framework is that between what is irreducibly singular or particular, on the one hand, and what is essentially general, universal or attributive on the other. The distinction is problematic, indeed, because one of its terms resists mereological analysis. The adoption of an exclusive whole/part framework, in other words, inevitably tends to favour the particular and the individual, at the expense of whatever is general or attributive. [...] In other words, the world and everything in it must be explained without the invocation of anything irreducibly attributive, relational, general, functional, unsaturated, or universal. We can call this Moore's particularism. (1999, pp. 205-206)

I have three reasons for rejecting Bell's interpretation.

Firstly, it is certainly true that in some of his early writings, particularly in Principia Ethica (1903), Moore makes extensive use of mereological analysis. But it is far from clear that he equally does so in $N J$, which was written some years before. In fact, in $N J$, Moore never uses explicitly any mereological analysis and he scarcely uses the words "part" and "whole". He uses the word "whole" only two times (NJ, pp. $181,186)$, and only once in the relevant mereological sense, when he says that concepts suitably related to truth or falsehood form "a whole to which we give the name of proposition" (NJ, p. 181, my italics). In contrast, at various parts he talks about propositions as if they were nothing but concepts related to each other (cf. NJ, pp. 180, 187, 188, 
189, 192), which is something completely compatible with an analysis that makes exclusive use of the resources of plural logic, without any commitment to composite wholes. It is true that in his attack against psychologism, at the beginning of $N J$ (p. 178), Moore restricts the use of the word "parts" to refer to existents. But it is evident that Moore admitted much more than existents. In fact, as we saw above, not only he admits the distinction between being and existence, but also claims that the realm of existence is somehow derived from the realm of being, because an existent is, ultimately, nothing but one or more concepts related to the concept existence, and the identity of a concept is never grounded or dependent on an existent.

Secondly, even if Moore was making an implicit use of a single framework of analysis, the mereological one, it is far from clear in what sense that framework cannot be applied to things that are not particulars but universals. For instance, the universals Justice and Courage could be said to be parts of the universal Virtue, as Plato might have thought; and, more evidently, the complex universal Polka-Dotted could be said to be composed of the universals Black and White. Similarly, while conceiving concrete particulars as bundles of universals, we could think of Sweet and White as parts of this sugar cube, this bundle of universals. After all, mereology, like logic, is supposed to be topic neutral. It is true that nominalistic spirits are fond of it, but there is no necessary connection between mereology and nominalism, including that extreme form of nominalism called "particularism". Leonard and Goodman, for instance, certainly make room for a mereology of universals when stating, before developing their standard mereology, that

[a]n individual or whole we understand to be whatever is represented in any given discourse by signs belonging to the lowest logical type of which that discourse makes use. What is conceived as an individual and what as a class is thus relative to the discourse within which the conception occurs. (Leonard \& Goodman, 1940, p. 45)

Thirdly, Bell seems to incur in the following categorial confusions. $\mathrm{He}$ equates being irreducibly attributive, relational, functional or unsaturated with being general or universal. At the same time, he equates being singular or individual with being particular. But, contrary to Bell's understanding, it seems perfectly possible for something to be general or universal without being irreducibly attributive, relational, functional or unsaturated; that is, something can be both individual or singular and general or universal. Platonic Forms are supposed to be 
like that: general or universal yet, at the same time, saturated, nonfunctional, self-sufficient objects. And, as I will argue later (section V), Moorean concepts seem to be just like Platonic Forms in this respect. Similarly, and contrary to Bell's understanding, it seems perfectly possible for something to be irreducibly attributive, relational, functional or unsaturated and particular, as when we talk about this particular shade of red that characterises this particular rose, numerically different from that particular shade of red that characterises that particular rose. Isn't precisely this unsaturated or attributive character the mark of properties understood as tropes? It is no coincidence that Simons (1994) prefers to name tropes "dependent particulars" instead of "abstract particulars", as they are called by others (e.g., Campbell, 1990; Williams, 1953). Therefore, we shouldn't take Bell's terms as if they were conforming two distinct families of equivalent categories, which stand against each other as if they were the opposite sides of a single dichotomy. Neither the terms of each family are equivalent nor the two families constitute the opposite sides of a dichotomy.

\section{IV}

The third and more recent interpretation that I want to discuss is due to MacBride (2018). According to MacBride, although everyone admits that Moore was offering a pluralistic ontology of many independent entities belonging to a single category,

[...] it isn't recognised that Moore intended the category in question, the category of concept, to succeed or supersede the categories of substance (particular) and attribute (universal). Commentators have made the conservative assumption that Moore's concepts must lie upon one side or other of that familiar division. So, they either interpret concepts as particulars, nominalism, or universals, a version of the bundle theory. But this is wrong, Moore's concepts are neither substances (particulars) nor attributes (universals). As a consequence, they fail to understand Moore's reasons for rejecting categorial dualism. (MacBride, 2018, pp. 43-44)

And then he adds:

Moore forsook the substance-attribute distinction altogether. According to this interpretation, Moore denied that the ultimate units of being are substances. And he denied that the ultimate units 
of being are attributes. Moore's concepts aren't attributes any more than they are substances; they are neither. Moore didn't give priority to one side of the distinction at the expense of the other but rejected the entire package that we have to take on board to conceive the world in terms of substance and attribute. (MacBride, 2018, p. 46)

MacBride calls the substance (particular)/attribute (universal) distinction "a familiar division" (2018, p. 43), which Moore was trying to overcome through his categorial monism. Elsewhere, more than a century after the publication of $N J$, and this time paying attention to our own philosophical Zeitgeist, MacBride insists that the distinction is still accepted by the philosophical community as "a metaphysical article of faith"; and not only as an undisputed distinction, but as a jointly exhaustive and mutually exclusive distinction, that is, as a dichotomy, a dualism that runs "deeper even than the dualism between mind and body" (MacBride, 2005, p. 565). That there are these two fundamental kinds of objects, is, according to him, "part of the philosophers' ABC, the expression of a distinction that requires no collusion amongst our intellectual community to secure assent" (MacBride, 2005, pp. 565-566). So, according to this so-called dogma, there is a real distinction-perhaps the most fundamental real distinction- between two wholly and clearly distinct kinds of objects, in such terms that, necessarily, every object must be either a substance (particular) or an attribute (universal); and nothing can be both a substance (particular) and an attribute (universal). Maybe there are no attributes (universals), as nominalists claim. Or maybe there are no substances (particulars), as some realists about attributes (universals) claim. This doesn't matter: every player in the game accepts the dichotomy; it just happens that some of them claim that one of the boxes is empty.

I think MacBride's move is conceptually obscure and historically unmotivated, and, for these very reasons, ultimately wrong.

Firstly, MacBride treats the substance/attribute distinction as (onto)logically equivalent to the particular/universal distinction. But, as I already said in the last section, they are not, and historical examples that prove my point go a long way back from the publication of $N J$. Let me illustrate my point by developing two counterexamples already mentioned against Bell's thesis: (i) Take the case of empiricists like Hume, Locke, or Berkeley. They might well have accepted that everything is either a substance or an attribute, and nothing is both, but they understood that attributes were particulars (i.e., tropes, individual accidents, 
property instances), not universals. Some think that even for Aristotle the attributes inhering in substances were particulars, not universals; and, given the strong influence of Aristotle in Medieval philosophy, it can be argued that particularized attributes can be found in Aquinas, Scotus, Ockham and Suarez too (Maurin, 2018, §1). Thus, contrary to the terms of MacBride's "familiar division", there might be things that are both particulars and attributes. (ii) Think about Justice, understood as a Platonic Form, as when you do when you accept at face value the truth of the sentence "Justice is a virtue". If we follow the superficial grammar of this truth, then its referent seems to be a substance: we are not saying of some $x$ that it is just; we are predicating something of Justice itself. That is, we are treating Justice as a substance, at least in one obvious sense: being a subject of reference and predication. Yet Justice still may be said to be a universal, at least in a primary and obvious sense: it is a general attribute, one that, at least in principle, may run through many things, since if there are just actions at all, then they are so in virtue of somehow participating in Justice itself.

So, my first objection to MacBride's point is that, since the substance/attribute distinction is not (onto-)logically equivalent to the particular/universal distinction, it is not clear what distinction Moore was trying to debunk, if any.

Secondly, it is clear that, way before Moore and Russell's assault, and way outside Cambridge, MacBride's "familiar division" was not taken as a sacrosanct metaphysical dichotomy. Far from that. On one hand, since the pre-Socratics, many philosophers have bet on entities that go beyond the terms of the "familiar division", that is, philosophers for whom MacBride's conflated distinction, taken at face value, was certainly not exhaustive. Think about processes, stuffs, laws of nature, holes, shadows, boundaries, languages, thoughts, truths, etc. Are these substances (particulars), attributes (universals), or something sui generis? For example, take a process such as an explosion or a stuff such as water: are they attributes (universals) instantiated in space-time, substances (particulars) in their own right, or something wholly sui generis? Similar questions can be raised for each of the kinds of entities aforementioned. On the other hand, even more neutral distinctions, drawn in less technically loaded terms, like the one between thing and quality, or the one between subject and predicate, or the one between the that and the what, the this and the such, being and way of being, etc., have never been taken as uncontroversial real distinctions. This can be said, in general, of Eastern philosophers, who have been generally reluctant to all real distinctions. Within the Western tradition, it may 
be said of many (Aristotle and Scotus included), and it can certainly be said at the very least of Descartes, Spinoza, and Nietzsche, to name three philosophical giants. ${ }^{7}$ Furthermore, what seems to me to count directly against MacBride's interpretation is that Bradley himself, the main target of Moore and Russell's coup, was perhaps one of the most ardent enemies of any real distinction. Bradley was particularly suspicious of any ontological category insofar as they are all thought-like. He definitely abhorred the distinction between the that and the what. And concerning the very idea of judgment, he was openly opposed to the idea that the judgment was somehow the union of a subject and a predicate, an object and a property, a substance and an attribute, or a particular and a universal: "It is not true that every judgment has two ideas. We may say on the contrary that all have but one" (Bradley, 1922, p. 11, my italics). And this one was, for Bradley, neither a what nor a that, but something that somehow transcended both of these terms. Substantive/ adjective, relation/quality, thought/reality, and other prominent alleged real distinctions, were, for Bradley, just "vicious abstractions", distorted images, imperfect ways of attempting to grasp the supra-relational Absolute. For Bradley, only immediate, pre-relational experience gives us a hint of the supra-relational Absolute, which seems ultimately elusive, ineffable, unthinkable. And it can give us a hint of the Absolute precisely because it presents itself as one experiential given whole, where no thought-like, i.e., relational, distinctions are present. In immediate experience we cannot even find a real or non-arbitrary distinction between subject and object, object ${ }_{1}$ and object $_{2}$, fact ${ }_{1}$ and fact f $_{2}$. These only come after immediate experience is teared apart by relational thought. ${ }^{8}$

${ }^{7}$ Here is some textual evidence for this. Descartes: "a conceptual distinction is a distinction between a substance and some attribute of that substance without which the substance is unintelligible; alternatively, it is a distinction between two such attributes of a single substance. Such a distinction is recognized by our inability to form a clear and distinct idea of the substance if we exclude from it the attribute in question, or, alternatively, by our inability to perceive clearly the idea of one of the attributes if we separate it from the other." (1985, I.62, italics in the original). Spinoza: "there is nothing outside the intellect through which a number of things can be distinguished from one another except substances, or what is the same (...), their attributes" (1994, IP4d, my italics). After all, according to Spinoza, an attribute is nothing but "what the intellect perceives of a substance, as constituting its essence" (Spinoza 1994, ID4). Nietzsche: "Fundamental solution: we believe in reason, but this is the philosophy of grey concepts; language is built in terms of the most naive prejudices// now we read disharmonies and problems into things because we think only in the form of language-thus believing in the 'eternal truth' of 'reason' (e.g., subject, predicate, etc.).” (2003, p. 110, italics in the original).

${ }^{8}$ See Bradley (1930, ch. 15) and Candlish (2007, ch. 2). Similar understandings 
Why, then, should Moore have been so concerned, as MacBride claims, in rebelling against a distinction that not only wasn't a commonly accepted metaphysical dogma, but that wasn't admitted as a real distinction at all by Bradley himself, that is, by the main figure of the movement against which Moore and Russell were, allegedly, rebelling? I don't see any reason. We can understand the revolutionary character of Moore's philosophy when we attend to his objectivism and his radical pluralism, and then contrast these features with the mentalist and holistic background dominant by then. But we don't understand Moore's novelty if we focus on an undetectable, and certainly not revolutionary, animadversion against a dichotomy that can hardly be seen as a "metaphysical article of faith". True, Moore did say that to find empirical or contingent propositions, as opposed to a priori or necessary propositions we were forced to "descend to purely existential propositions - propositions which do not involve the notions of substance and attribute" ( $N J$, p. 186), and that existential propositions only assert the existence of a concept, without appealing to the substance-attribute structure (NJ, pp. 185-186). But Moore shows no animadversion against MacBride's so-called "dogma". If anything, those statements only show that Moore, just like many others before and after him, thought that ordinary subject-predicate discourse isn't able to capture all reality. And Bradley, perhaps the main target of "the new philosophy", would have been the first one to agree with him on this.

\section{V}

What are Moorean concepts then?

It is difficult, perhaps impossible, to define with sufficiency and without circularity the fundamental beings of any ontology. At most one can point to their salient features or roles. As I have already suggested, Moorean concepts can be easily equated to Platonic Forms. Of course,

\footnotetext{
of "pure experience" or "the given" can be traced in William James, whose work was widely known and influential by that time too, and who thought such experience was just "one great blooming, buzzing confusion" (1981, p. 462). In fact, the list of philosophers that do not adhere to what MacBride's takes as a "dogma" is long and old and persistent; so long and old and persistent, that we can hardly talk about its members as being heretics or revolutionaries. They surely were rebelling against certain pre-philosophical or common-sensical intuitions, but not against some entrenched philosophical dogma. And even if there has ever been such a dogma, it would be at least parochial to think that the revolution against it started in Cambridge, by the end of the $19^{\text {th }}$ century (see Bell, 1999 for more considerations against the myth that analytic philosophy was a "British coup").
} 
there is discussion about both what Platonic Forms really are too. But I will not enter into this scholarly debate in any detail; this goes beyond the scope of this paper. I will only take as mine pretty standard accounts regarding this question, such as Harte's (2019) or Irwin's (1999), both of which are distilled from Plato's so-called middle dialogues, in particular Phaedo, Symposium, and Republic. Thus, for instance, if we attend to Harte's account, Platonic Forms can be characterised (typically in contrast with their counterparts, the so-called "concrete particulars") appealing to the following salient features or roles: (i) they are primary or fundamental beings; (ii) they are responsible for other phenomena; for instance, the Form Justice somehow grounds or explains or causes just actions; (iii) they are the "primary bearers" of general terms that are used to describe those aspects of phenomena for which Forms are ontologically responsible; typically, Form F, the F itself, is the referent of the answer to the standard Socratic question "What is F?", a question that typically points to a "common nature"; (iv) each of them is a unity, a oneness, so whereas there is only one Form Justice, there may be many just actions, which are just and fall under the general term "just" in virtue of somehow participating in the unique Form Justice; (v) they are privileged (some say the only) objects of knowledge: they are what reason, though not perception, knows when it knows; they are intelligible, not perceptible; (vi) they are transcendent, not in flux, changeless; in other words, they are abstract, if by this we mean atemporal; and (vii) they are mind-independent. ${ }^{9}$

As it happens, Moorean concepts have almost identical features. Just like Platonic Forms, Moorean concepts are fundamental or primary entities, in an ontological, explanatory, epistemic, and semantic sense. The textual evidence in $N J$ that grants this conclusion is abundant. To the risk of repeating myself, we see that features (i) and (ii) receive clear expression when Moore claims that "[a] concept is not in any intelligible sense an 'adjective,' as if there were something substantive, more ultimate than it" and that "the concept turns out to be the only substantive or subject, and no one concept either more or less an adjective than any other" ( $N J$, pp. 192-193). Additional evidence comes from his claim that concepts cannot be obtained through abstraction from our minds or from material objects, since these are grounded in judgments, that is, they "can, if anything is to be true of them, be composed of nothing but concepts" (NJ, p. 182), and in particular from the fact that all

${ }^{9}$ See Harte (2019, pp. 456-458, 465); cf. Irwin (1999). Similar features can be traced in contemporary versions of Platonism; see Cowling (2017). 
explanations of concepts in terms of other kinds of things are viciously circular: they already "presuppose the nature of the concept, as a genus per se, irreducible to anything else", because, ultimately, "[i]dentity of content is presupposed in any reasoning..." (NJ, pp. 178-179). The last sentences of $N J$ sum up the pervasive fundamentality of concepts:

From our description of a judgment, there must, then, disappear all reference either to our mind or to the world. Neither of these can furnish "ground" for anything, save in so far as they are complex judgments. The nature of the judgment is more ultimate than either, and less ultimate only than the nature of its constituents - the nature of the concept or logical idea. (NJ, p. 193)

Features (iii) and (iv) receive expression when Moore claims that the apparent diversity of things "is only derived" from that which he takes to be the real "starting-point": the existence of self-identical concepts standing in distinct relations to other self-identical concepts $(N J, \mathrm{p}$. 182), which are "universal meaning[s]", "content[s]", "the symbolized" (NJ, p. 177), "possible objects of thought" (NJ, p. 179), "something which we mean" (NJ, p. 180), "logical idea[s]" (NJ, p. 193).

Finally, features (v), (vi), and (vii) receive expression when Moore claims that concepts, before entering into a relation with a thinker, "must already be something"; that they are "incapable of change"; that "[i]t is indifferent to their nature whether anybody thinks them or not" (NJ, p. 179); and later, when he claims that not only the world is wholly "formed of concepts", but also that concepts "are the only objects of knowledge" (NJ, p. 182).

Now that we have seen that Platonic Forms and Moorean concepts are not relevantly different from each other, should we say that they are sui generis entities, wholly unfamiliar to us? Not necessarily. Plato doesn't talk about his Forms using words such as "universals", "properties", or "meanings"; nor does he talk about them using the word "particulars". Plato refers to Forms, in more general terms, as "ta onta", i.e., "the beings", or as "ousie", i.e., "substances", "essences" (Harte, 2019, p. 456; see also Irwin, 1999). Nor does Moore talk about his concepts directly in the former terms; he prefers the word "concepts", of course. Yet he, more or less like Plato, also understands that there is nothing "more substantive" or "more ultimate" than simple concepts (NJ, p. 192). Moore could well have used the word "Forms" or "Ideas" for his concepts, whereas Plato could have well used the word "concepts" for his Forms or Ideas. The dispute is not terminological, however. The question is about 
the roles played and the features exhibited by both Platonic Forms and Moorean concepts. And I am now ready to argue that Moorean concepts, just like Platonic Forms, deserve to fall under the still technical but more familiar name of "individual substances". Again, not because this last term has its meaning written in stone, but because the features and roles that individual substances are expected to have are also had by Moorean concepts.

What are the salient features and roles of individual substances? To take a comprehensive and more or less neutral account, let's attend to Robinson's criteria of substancehood. As he puts it:

[T] here are at least six overlapping ideas that contribute to the philosophical concept of substance. Substances are typified as:

i. being ontologically basic_-substances are the things from which everything else is made or by which it is metaphysically sustained; ii. being, at least compared to other things, relatively independent and durable, and, perhaps, absolutely so;

iii. being the paradigm subjects of predication and bearers of properties;

iv. being, at least for the more ordinary kinds of substance, the subjects of change;

v. being typified by those things we normally classify as objects, or kinds of objects;

vi. being typified by kinds of stuff. (Robinson, 2020, §1)

It is very unlikely that an account of substance can meet all these criteria in the highest degree. Typically, success on meeting one criterion carries failure on meeting another criterion. For instance, Platonic Forms seem to meet, quite obviously, criteria i. and ii. in a high degree. Yet this apparent straightforward fulfilment of these two criteria carries with it, as a trade-off, the failure to meet in any straightforward fashion criteria iv. and v. But this is a problem for any ontology. Aristotle's ontology and, more generally, common-sense ontologies, will typically have the reverse problem.

Not surprisingly, Moorean concepts meet criteria i. and ii. in strong terms. They are ontologically basic in such a way that everything is ultimately analyzable in terms of them. Moreover, Moorean concepts are atemporal, so they are "durable" in the highest degree, and they stand to each other in external relations, that is, relations that do not enter into their constitution or identity, which is what grants their ontological independence. Of course, Moorean concepts do not seem 
to satisfy well criterion iv., probably for reasons already discussed, but in this regard they are in a similar position to Tractarian objects (Wittgenstein, 1974), Armstrong's ultimate states of affairs or atomic "thick particulars" (Armstrong, 1997), and the ultimate temporal parts of a perdurantist and four-dimensionalist ontology such as Lewis' (Lewis, 1986). In all these ontologies, change is explained in terms of changeless objects somehow standing in certain relations to times. Lastly, Moorean concepts do seem to meet criteria iii., v. and vi. too, yet in a less straightforward way. No ordinary object or stuff is taken to be basic, but, after proper analysis, all ordinary object or stuff is nothing but many concepts in relation. For Moore, an ordinary object like a horse "dissolves", after analysis, into basic substances in relation, say mammal-brown-existence-now-here. What Moore is saying to us is that what we take to be an ordinary substance, a concrete particular object or stuff is just "what appears to be more substantive", since, ultimately, there are no concrete particulars at all (NJ, p. 192). Ultimately, all we have are concepts standing in relations to other concepts. All predication, all functionality, or unsaturated character ultimately seems to rest on the relations in which Moorean simple concepts stand to each other. How concepts stand to each other, their very relatedness, seems to be an unspeakable feature of Moore's system. In fact, there is no direct evidence of Moore being ontologically committed to the relations into which concepts stand to each other. If Moore's theory were to suffer Quinean regimentation in order to extract its ontological commitments, it would contain only concepts. In other words: although concepts can be named, their propositional form, the way in which they stand to each other can only be shown. As Moore said, "[w]ith regard to the special method of composition I said nothing. There would need, I think, to be several kinds of ultimate relation between concepts" (letter to Russell, quoted in MacBride, 2018, p. 53).

What prevents us from taking Moorean concepts as individual substances then? My hypothesis is the following: the same factor that prevents many from taking Platonic Forms as individual substances, namely: the Aristotelian legacy or prejudice. Aristotle, in his Peri Ideôn (On Ideas), famously criticized Platonic Forms for being, allegedly, a confusion between particulars and universals, and argued that only particulars were individual substances (Fine, 1993). Whether Aristotle's objections against Platonic Forms are sound or not is something still disputed, but there are good reasons to believe that they are not as effective as they are supposed to be (Shields, 2019). For my purposes, it is sufficient to say that this scholarly debate is still open and that, in any 
case, Aristotle's contemporary heirs do not seem to bother for arguing against the prima facie substantial character of Platonic Forms. They seem to take for granted that they are not individual substances. To illustrate my point, take Lowe's definition of substance:

$x$ is a substance if and only if $x$ is a particular and there is no particular $y$ such that $y$ is not identical with $x$ and the identity of $x$ depends on the identity of $y$. (Lowe, 1998, p. 151)

Platonic Forms don't fall under this definition. They are not particulars; they are transcendent universals. ${ }^{10}$ But what stops Lowe for admitting Platonic Forms, transcendent universals, as substances? Lowe himself offers the answer:

I have, of course, made it part of the definition of "substance" that a substance is a particular, which may seem somewhat ad hoc. Why, it may be asked, shouldn't a universal qualify as a "substance", so long as it does not depend for its identity upon anything other than itself? I confess that this verdict may indeed appear a little arbitrary if one espouses a "Platonic" or "transcendent" realism concerning universals, whereby they exist independently (in the generic sense) of their particular instances because they may lack such instances altogether. But my own preference is for an "Aristotelian" or "immanent" realism concerning universals, which asserts on the contrary that a universal can only exist if there are (somewhere and somewhen) particulars that are instances of it. Thus, on this view, a universal is generically existentially dependent upon its particular instances. (Lowe, 1998, p. 159)

As it can be appreciated, Lowe denies the status of substances to Platonic Forms only because he is sticking to the Aristotelian paradigm. But he provides no reason for his preference. Indeed, he admits that the exclusion of Platonic universals "may indeed appear a little arbitrary" (my italics). It is just an option that doesn't fit well with his "own preference for an 'Aristotelian' or 'immanent' realism about universals". Lowe is openly admitting to be another victim of the Aristotelian prejudice. To conceive universals as irreducibly attributive, relational, functional, unsaturated, that is, as ontologically dependent

${ }^{10}$ This statement tolerates exceptions. Some Platonic Forms may well be understood as abstract particulars (e.g., numbers, sets). See footnote 3 above. 
entities, is to conceive them through Aristotelian spectacles. Through these spectacles, the privileges of substancehood belong exclusively to concrete particulars. For the Aristotelian, these are the fundamental and ontologically independent beings upon which everything else depends; they have ontological, explanatory, epistemic, and semantic priority. Thus, Aristotelian or immanent universals lack autonomous existence and identity. In fact, according to a standard account, they do not enjoy independent existence and their identity can only be obtained through a mental process of abstraction from the single whole that is a concrete particular substance, in such a way that there is an inverse relation between the identity and the actuality of the universal: the closer we get to the former, the further we get from the latter, and viceversa (Scaltsas, 1994, pp. 4-5, 196-197). But surely Moore doesn't call his ontology "Platonic" to suggest that we must understand it through Aristotelian spectacles. Moore knew the classics very well (Braithwaite, 1970; Moore, 1968; Nelson, 1967). It seems fair to assume that what he meant by "Platonic" was literally Platonic or something very close to it. And Platonism puts Aristotelianism over its head: from an ontological, explanatory, epistemic, and semantic point of view, abstract objects, transcendent universals included, are basic and fundamental; concrete particulars, the whole realm of sensible objects, if it exists at all, is grounded, explicable or ultimately analysable in terms of abstract objects (Carmichael, 2016; Cowling, 2017; Harte, 2019; Irwin, 1999).

Thus, truly, there seems to be no sufficient reason for denying the status of individual substances to Platonic Forms. And the same goes for Moorean concepts. Both satisfy most marks of substance in a high degree. They just happen to be not what common sense takes to be individual substances, that is, concrete particulars, particulars such as horses, persons and trees, conceived in Aristotelian fashion, located "somewhere" and "somewhen", that somehow instantiate universals. For Plato and Moore, these ordinary middle-sized dry goods are simply not what they appear to be.

The fact that Moorean concepts, just like Platonic Forms, deserve the status of individual substances is well illustrated when we think about the usual a priori argument that is given to show that positing abstract objects is the best way to make sense of true sentences involving singular terms that at least seem to refer to them (Loux \& Crisp, 2017, pp. 26-29; Cowling, 2017, §1.2). The argument is quite simple: (i) if an assertoric sentence is true, then its singular terms refer; (ii) if its singular terms refer, then the objects referred by those singular terms exist; (iii) there are true assertoric sentences 
which contain singular terms that refer to objects that can only be abstract objects (among which, numbers, propositions, transcendent universals are salient cases); therefore, (iv) there are abstract objects. Examples of this sort of abstract reference are abundant. Here is a representative sample (two involving reference to numbers, i.e., species of abstract particulars, and three involving reference to transcendent universals): " 2 is a prime number"; "10 is greater than 2"; "justice is a virtue"; "justice and courage are two distinct virtues"; "red is darker than yellow". Obviously, any nominalist will try to offer paraphrases of these sentences to show that their superficial grammar, after proper analysis, does not involve abstract reference, and therefore does not commit us to the existence of abstract objects. But this is beside my point. I am not defending the soundness of the argument nor the truth of its premises. My point is that, if those examples count in favour of the existence of abstract objects, then, when they refer to universals, they directly favour their transcendent understanding, which in no obvious sense takes them to be attributive, relational, functional, unsaturated or somehow ontologically dependent upon other entity or entities. In those cases, universals are posited as the semantic values of singular terms, not of predicates.

In Strawson (1959) we find a less prejudiced account of individual substances. Strawson admits both particular and nonparticular individuals. Following Strawson's lead, it is clear that all Moorean concepts qualify perfectly well as individual substances, among which some are particulars (numbers, spaces, and times) and some are non-particulars (transcendent universals like virtues, kinds, colours, and the like). All of them are abstract, since all spatial and temporal location is a by-product of empirical propositions, and these are nothing but concepts-in-relation involving the concept existence and a time concept. With respect to Moorean complex concepts that do not involve numbers, spaces or times, that is, concepts that are ultimately analysable in terms of universals alone, Moore's position may be assimilated to the one drawn by Strawson when discussing Leibnizian monads. Leibnizian monads could well be thought, Strawson claims, not as particulars that fall into concepts or universals, but as concepts or universals themselves (complete individual notions), that is, as "nonparticular individuals" (Strawson, 1959, pp. 124-127). In this ontology, the Identity of Indiscernibles is part of the package, since numerical difference and numerical identity are not brute facts but facts that are made intelligible in terms of universals: 
If one universal differs numerically from another, then it must be possible in principle to state the difference in general, i.e., universal, terms. Two universals can share the same partial designations: red and blue are both "colours". But they cannot share the same complete designation. For difference of universals is difference of meaning of universal terms. (Strawson, 1959, p. 127)

Strawson notes that "acknowledging that the individuals of the system are not particulars at all, but universals or types or concepts (...) is, perhaps, a price that a mathematically-minded metaphysician is quite willing to pay" (1959, p. 124). This fits perfectly well with the stance that Moore had in the early stage of his career: he was committed to the Identity of Indiscernibles (NJ, p. 182) and he was happy to pay the price involved: he was "pleased to believe" that his system was "the most Platonic system of modern times".

\section{References}

Armstrong, D. M. (1997). A world of states of affairs. Cambridge University Press.

Baldwin, T. (1990). G. E. Moore. Routledge.

Basile, P. (1999). Experience and relations: An examination of $F$. $H$. Bradley's conception of reality. Paul Haupt.

Bell, D. (1999). The revolution of Moore and Russell: A very british coup? In A. O’Hear (Ed.), German Philosophy since Kant (pp. 193-208). Cambridge University Press.

Bradley, F. H. (1922). The principles of logic, Vol. I ( $2^{\text {nd }}$ ed.). Oxford University Press.

Bradley, F. H. (1930). Appearance and reality: A metaphysical essay ( $2^{\text {nd }}$ ed., $9^{\text {th }}$ imp.). Clarendon Press.

Braithwaite, R. B. (1970). George Edward Moore, 1873-1958. In A. Ambrose, \& M. Lazerowitz (Eds.), G. E. Moore: Essays in retrospect (pp. 17-33). Routledge.

Campbell, K. (1990). Abstract particulars. Basil Blackwell.

Candlish, S. (2007). The Russell / Bradley dispute and its significance for twentieth-century philosophy. Palgrave Macmillan.

Carmichael, C. (2016). Deep Platonism. Philosophy and Phenomenological Research, 92(2), 307-328. https://doi.org/10.1111/phpr.12190

Cowling, S. (2017). Abstract entities. Routledge.

Descartes, R. (1985). Principles of philosophy. In The philosophical writings of Descartes, Vol. 1 (ed. trans. J. Cottingham, R. Stoothoff \& 
D. Murdoch, pp. 177-291). Cambridge University Press. https:// doi.org/10.1017/CBO9780511805042

Eklund, M. (2017). A world formed of concepts: The early metaphysics of G. E. Moore. English version of a paper published in G. Masterton, K. Matsubara and K. Solin (eds.), Från Skaradjäkne till Uppsalaprofessor (Festschrift for Lars-Göran Johansson), Uppsala Philosophical Studies. https://www.academia.edu/33478109/A_ World_Formed_of_Concepts_The_Early_Metaphysics_of_G [Last visit: 28/05/20].

Fine, G. (1993). On ideas: Aristotle's criticism of Plato's theory of forms. Clarendon Press.

Frege, G. (1980). The foundations of arithmetic (trans. J. L. Austin). Northwestern University Press.

Harte, V. (2019). Plato's metaphysics. In G. Fine (Ed.), The Oxford handbook of Plato ( $2^{\text {nd }}$ ed., pp. 455-480). Oxford University Press.

Hochberg, H. (1962). Moore's ontology and non-natural properties. The Review of Metaphysics, 15(3), 365-395. https://www.jstor.org/ stable/20123890

Hornsby, J. (1997). Truth: The identity theory. Proceedings of the Aristotelian Society, New Series, 97, 1-24. https://www.jstor.org/ stable $/ 4545250$

Irwin, T. H. (1999). The theory of forms. In G. Fine (Ed.), Plato 1: Metaphysics and Epistemology (pp. 143-170). Oxford University Press.

James, W. (1981). The principles of psychology. Harvard University Press.

Leonard, H. S., \& Goodman, N. (1940). The calculus of individuals and its uses. The Journal of Symbolic Logic, 5(2), 45-55. https://doi. org/10.2307/2266169

Lewis, D. (1986). On the plurality of worlds. Blackwell.

Loux, M., \& Crisp, T. (2017). Metaphysics: A contemporary introduction ( $4^{\text {th }}$ ed.). Routledge.

Lowe, E. J. (1998). The possibility of metaphysics: Substance, identity, and time. Clarendon Press.

MacBride, F. (2005). The particular-universal distinction: A dogma of metaphysics? Mind, New Series, 114(455), 565-614. https://www. jstor.org/stable/3489007

MacBride, F. (2018). On the genealogy of universals: The metaphysical origins of analytic philosophy. Oxford University Press.

Maurin, A.-S. (2018). Tropes. In E. Zalta (Ed.), The Stanford encyclopedia of philosophy (Summer 2018 Edition). https://plato.stanford.edu/ archives/sum2018/entries/tropes/ 
Moore, G. E. (1899). The nature of judgment. Mind, New Series, 8(30), 176-193. http://www.jstor.org/stable/2247657

Moore, G. E. (1903). Principia ethica. Cambridge University Press.

Moore, G. E. (1968). An autobiography. In P. A. Shilpp (Ed.), The philosophy of G. E. Moore (pp. 1-39). Open Court.

Nelson, J. (1962). Mr. Hochberg on Moore: Some corrections. The Review of Metaphysics, 16(1), 119-132. https://www.jstor.org/ stable/20123927

Nelson, J. (1967). Moore, George Edward. In P. Edwards (Ed.), The encyclopedia of philosophy, Vol. V (pp. 372-381). Macmillan \& Free Press.

Nietzsche, F. (2003). Writings from the late notebooks (ed. R. Bittner, trans. K. Sturge). Cambridge University Press.

Preti, C. (2013). The origin and influence of G.E. Moore's 'The Nature of Judgment'. In M. Textor (Ed.), Judgement and truth in early analytic philosophy and phenomenology (pp. 183-205). Palgrave Macmillan.

Robinson, H. (2020). Substance. In E. Zalta (Ed.), The Stanford encyclopedia of philosophy (Spring 2020 Edition). https://plato. stanford.edu/archives/spr2020/entries/substance/

Russell, B. (1959). My philosophical development. George Allen \& Unwin. Ryle, G. (1970). G. E. Moore's 'The Nature of Judgment'. In A. Ambrose, \& M. Lazerowitz (Eds.), G. E. Moore: Essays in retrospect (pp. 89101). Routledge.

Scaltsas, T. (1994). Substances and universals in Aristotle's metaphysics. Cornell University Press.

Schaffer, J. (2010). Monism: The priority of the whole. Philosophical Review, 119(1), 31-76. https://doi.org/10.1215/00318108-2009-025

Shields, C. (2019). Plato and Aristotle in the Academy. In G. Fine (Ed.), The Oxford handbook of Plato, ( $2^{\text {nd }}$ ed., pp. 645-667). Oxford University Press.

Simons, P. (1994). Particulars in particular clothing: Three trope theories of substance. Philosophy and Phenomenological Research, 54(3), 553-575. https://doi.org/10.2307/2108581

Spinoza, B. (1994). Ethics. In E. Curley (Ed.), A Spinoza Reader: The "Ethics" and Other Works (pp. 85-265). Princeton University Press.

Strawson, P. F. (1959). Individuals: An essay in descriptive metaphysics. Methuen.

Williams, D. C. (1953). On the elements of being: I. The Review of Metaphysics, 7(1), 3-18. 
Wittgenstein, L. (1974). Tractatus Logic-Philosophicus (trans. D. F. Pears \& B. F. McGuinness). Routledge \& Kegan Paul.

Yi, B. (1999). Is two a property? The Journal of Philosophy, 96(4), 163190. https://doi.org/10.2307/2564701

Received 20 th July 2020; accepted $21^{\text {st }}$ October 2020. 